Çukurova Üniversitesi Mühendislik Fakültesi Dergisi, 36(3), ss. 659-668, Eylül 2021

Cukurova University Journal of the Faculty of Engineering, 36(3), pp. 659-668, September 2021

\title{
Dikkat Modülleri ile Oluşturulmuş Derin Öğrenme Modelini Kullanarak Pamuk Hastalığının Tespiti \\ Mesut TOĞAÇAR ${ }^{* 1}$

\author{
${ }^{1}$ Fırat Üniversitesi, Teknik Bilimler Meslek Yüksekokulu, Bilgisayar Teknolojileri \\ Bölümü, Elazı̆g
}

Geliş tarihi: 31.03 .2021

Kabul tarihi: 13.09 .2021

\section{$\ddot{O} z$}

Pamuk, dünya genelinde önemli bir endüstri sektörü olup, tarıma dayalı ülkelerde ekonomik kalkınmanın en önemli faktörlerinden biridir. Ülkemiz, pamuk tarımına elverişli ülkeler arasında yer almaktadır ve genelde Akdeniz ile Güneydoğu Anadolu bölgesinde pamuk üretimi gerçekleştirilmektedir. Pamuk bitkisinden iç ve dış etmenlerden kaynaklı birçok hastalık görülebilmektedir. Araştırmacılar, pamuk hastalığının tespitini gerçekleştirmek ve verimli bir üretim elde edebilmek için son zamanlarda yapay zekâ tabanlı çalışmalara odaklanmışlardır. Bu çalışmada kullanılan veri kümesi; hastalıklı pamuk yaprağı, hastalıklı pamuk bitkisi, sağlam pamuk yaprağı ve sağlam pamuk bitki görüntülerinden oluşmaktadır. Önerilen yaklaşımda, veri büyütme tekniği ile dikkat modüllerinden oluşan derin öğrenme modeli birlikte kullanılmıştır. Çalışmanın analizlerinde, Olasılıksal Dereceli Azalma (ODA) ve Uyarlanabilir Moment Tahmini (UMT) optimizasyon yöntemleri kullanılmıştır. Sınıflandırma sürecinde elde edilen en iyi genel doğruluk başarısı \%96,56 olmuştur.

Anahtar Kelimeler: Derin öğrenme, Dikkat modülleri, Pamuk hastalığı, Veri büyütme

\section{Detection of Cotton Disease Using Deep Learning Model Created with Attention Modules}

\begin{abstract}
Cotton is an important industrial sector worldwide and is one of the most important factors of economic development in countries based on agriculture. Our country is among the countries that are suitable for cotton agriculture and cotton production is generally carried out in the Mediterranean and Southeast Anatolia. Many diseases caused by internal and external factors can be seen in cotton plants. Researchers have recently focused on artificial intelligence-based studies to detect cotton disease and achieve efficient production. The dataset used in this study; it consists of diseased cotton leaf, diseased cotton plant, fresh cotton leaf and disease fresh plant images. In the proposed approach, the data augmentation technique and the deep learning model consisting of attention modules are used together. Stochastic Gradient Descent (SGD) and Adaptive Moment Estimation (ADAM) optimization methods were used in the analysis of the study. The best overall accuracy success achieved in the classification process was $96.56 \%$.
\end{abstract}

Keywords: Deep learning, Attention modules, Cotton disease, Data augmentation

*Sorumlu yazar (Corresponding author): Mesut TOĞAÇAR, mtogacar@firat.edu.tr 


\section{GíRiș}

Pamuk, tarıma dayalı tüm ülkelerinde ekonomik getirisi olan ve çeşitli sanayi kollarında işlev gören bitki türüdür. Dünya genelinde pamuk üretiminin en çok gerçekleştiği ülkeler arasında; Hindistan, Çin, ABD gelmektedir [1]. Türkiye'de pamuk üretiminde dünyada sayılı ülkeler arasında yer almaktadır. Ülkemizin Akdeniz, Ege ve Güneydoğu Anadolu bölgesinde pamuk yetiştiriciliği yoğun bir şekilde gerçekleştirilmektedir [2]. Şanlıurfa, Aydın, Hatay, Diyarbakır, Adana ve İzmir ön sıralarda yer alan şehirlerdir [3].

Pamuk bitkisinden elde edilen lifler ve yağlar sanayinin hammaddesi olarak kullanılmaktadır [4]. Ekonomik değeri yüksek olan bu bitkinin iklim şartlarına elverişli olarak yetiştirilmesi gerekir. Ülkemizde, sıcak ve sulama imkânı fazla olan bölgelerde pamuk yetiştirilmektedir [5]. Pamuk bitkisinde çevresel etmenlerden kaynaklı birçok hastalık meydana gelebilmektedir ve oluşan bu durum "pamuk hastalığı" olarak adlandırılmaktadır [6,7]. Pamuk hastalığının yaygınlaşması durumunda üretimdeki verim azalmakta ve ülke ekonomisine zarar verebilmektedir. Üreticiler tarafından pamuk hastalığının önüne geçebilmek için çeşitli önlemler alınmaktadır [8].

Araştırmacılar, ekonomik değeri yüksek olan pamuk bitkisinin verimini düşürmemek, sağlıklı bir şekilde kullanabilmek için teknolojik gelişmelere odaklanmış çalışmalar üzerinde durmaktadırlar. Son zamanlarda, pamuk hastalığının tespitinde yapay zekâ tabanlı birçok çalışma gerçekleştirilmiştir. Bunlardan bazıları incelenirse; Nikhil Shah ve arkadaşları [9], pamuk bitkisi görüntülerini kullanarak hastalıklı tür ve hastalıklı olmayan tür olmak üzere ikili bir sınıflandırma gerçekleştirmişlerdir. Onlar, görüntü verisine ön işlem adımlarını uygulamışlardır. Veri bölütleme, veri çoğaltma tekniklerini her bir görüntü için kullanmışlardır. Ardından, çok katmanlı yapay sinir ağ1 (YSA) modelini kullanarak sinıflandırma sürecini gerçekleştirmişlerdir. Onlar, analiz ölçümünde t-testini kullanmışlar ve elde ettikleri ortalama bağıl hata oranı $\% 5,1$ tespit etmişlerdir. Nirmal Chowdhary ve arkadaşları [10], pamuk hastalığını tespiti için görüntü işleme ve makine öğrenme yöntemlerini kullanmışlardır. Onlar, her bir görüntï verisine ön işlem adımlarını "Uyarlanabilir histogram eşitleme (UHE)-Adaptive histogram equalization (AHE) ve k-ortalama bölütleme" uygulamışlardır.

Ardından makine öğrenme yöntemleri; destek vektör makineleri (DVM)-Support Vector Machines (SVM), en yakın komşu (EYK)-nearest neighbors (KNN) yöntemi ve YSA modeli ile sınıflandırmışlardır. En iyi sınıflandırma performansını YSA modeli ile elde etmişler ve \%89 oranında bir başarı sağlamışlardır. Nimra Pechuho ve arkadaşları [11], pamuk hastalığın tespitinde derin öğrenme modelini kullanmışlardır. Onlar çalışmasında, Inception V3 modeli ile veri kümesini eğitmişler ve Softmax yöntemi ile modelin sınıflandırılmasını gerçekleştirmişlerdir. Sınıflandırma sürecinde elde ettikleri genel doğruluk başarısı \%91 olarak gerçekleşmiştir. Mva Gulhane ve arkadaşları [12], pamuk hastalığının tespiti için ön işlem adımları ve makine öğrenme yöntemini kullanmışlardır. Onlar, ön işlem adımı olarak renkli görüntü bölütleme yöntemini uygulamışlardır. Sinıflandırma sürecini DVM yöntemi ile gerçekleştirmişler ve \%90,5 oranında genel doğruluk başarısı elde etmişlerdir.

$\mathrm{Bu}$ makalenin amacı, pamuk hastalığının tespitini yapay zekâ tabanlı önerilen yaklaşımla başarılı bir şekilde gerçekleştirmektir. Bunun için görüntü kümesi ön işlem adımlarından geçirilerek dikkat modüllerinden oluşturulan evrişimsel sinir ağ1 (ESA)-convolutional neural network $(\mathrm{CNN})$ modeli eğitilmesi hedeflenmektedir. Bu çalışmada diğer bölümler ise şu şekildedir; veri kümesi ile ilgili bilgiler 2. bölümde verilmiştir. Çalışmanın analizinde kullanılan yöntem ve model hakkında bilgiler 3. bölümde verilmiştir. Deneysel analizler ve sonuçları 4. bölümde yer almıştır. 5. ve 6 . bölümler, sırasıyla Tartışma ve Sonuç bölümünden oluşmuştur. 


\section{VERİ KÜMESİ}

Veri kümesi, pamuk yaprağı ve bitki görüntülerinden oluşmaktadır ve Kaggle web sitesinde erişime sunulmuştur. Veri kümesi, dört sınıftan oluşmaktadır; hastalıklı pamuk yaprağı, hastalıklı pamuk bitkisi, sağlam pamuk yaprağı ve sağlam pamuk bitkisi. Sınıf türlerine ait örnek görüntüler Şekil 1'de gösterilmiştir. Her bir görüntü verisi JPEG dosya uzantılı olup, 24 bit derinliğindedir ve görüntülerin çözünürlüğü sabit değildir. Veri kümesi, test ve eğitim kümesi olarak iki gruba ayrılmıştır. Eğitim veri kümesinde toplam 1951 imge yer almaktadır. Test veri kümesinde toplam 349 imge yer almaktadır [13]. Toplam 2300 görüntüden oluşan veri kümesinin istatistiksel bilgileri Çizelge 1'de verilmiştir. Sınıf tabanlı istatistiksel bilgiler ise Şekil 2'de gösterilmiştir.

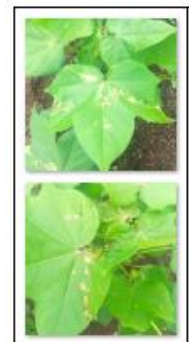

(a)

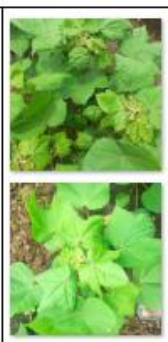

(b)

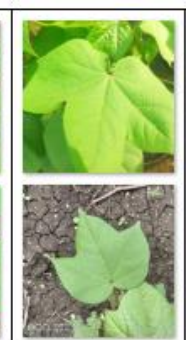

(c)

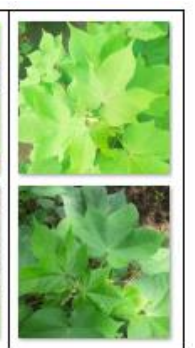

(d)
Şekil 1. Pamuk veri kümesinin sinıf görüntüleri a) hastalıklı yaprak, b) hastalıklı bitki, c) sağlam yaprak, d) sağlam bitki

Çizelge 1. Eğitim ve test verilerinin istatistiksel bilgileri

\begin{tabular}{|l|l|c|c|}
\hline \multicolumn{1}{|l}{$\begin{array}{l}\text { Veri } \\
\text { kümesi }\end{array}$} & Sınıf & $\begin{array}{r}\text { Görüntü } \\
\text { sayısı }\end{array}$ & \multirow{2}{*}{ Toplam } \\
\hline \multirow{4}{*}{ Eğitim } & Hastalıklı yaprak & 288 & \multirow{2}{*}{1951} \\
\cline { 2 - 3 } & Hastalıklı bitki & 815 & \\
\cline { 2 - 3 } & Sağlam yaprak & 427 & \multirow{2}{*}{349} \\
\cline { 2 - 3 } & Sağlam bitki & 421 & \\
\hline \multirow{4}{*}{ Test } & Hastalıklı yaprak & 58 & \multirow{2}{*}{54} \\
\cline { 2 - 3 } & Hastalıklı bitki & 106 & \\
\cline { 2 - 3 } & Sağlam yaprak & 92 & \\
\cline { 2 - 3 } & Sağlam bitki & 93 & \\
\hline
\end{tabular}

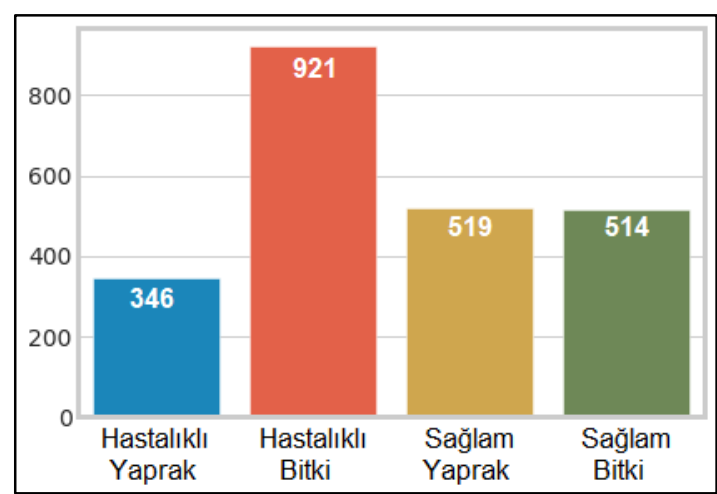

Şekil 2. Pamuk veri kümesinin sınıf bazlı istatistiksel bilgileri

\section{TEKNİK VE YÖNTEMLER}

\subsection{Veri Büyütme Tekniği}

Veri büyütme tekniği; görüntülerin farklı varyasyonlarını oluşturarak veri kümesindeki görüntü çeşitliliğini arttırmayı ve derin öğrenme modellerinin aşırı uyum (overfitting) probleminden kurtarmayı hedefler. Başka bir değişle; model küçük kapasiteli veri setleri ile eğitilirken ortaya çıkan ezberleme probleminden kurtarmaya çalışır. Böylece daha genel bir modelin eğitilmesi amaçlanır. Veri büyütme tekniğinde; çevirme, kesme, kaydırma, yakınlaştırma, doldurma gibi parametreler yer almaktadır [14]. Bu çalışmada, Çizelge 2'de belirtilen parametreler kullanıldı ve yalnızca eğitim verilerine uygulandı. Veri büyütme tekniğinin kodları python yazılımında tasarland ve keras kütüphanesinin "Image Data Generator" fonksiyonu kullanılarak işlemler gerçekleşti. Çalışmanın analizinde kullanılan veri büyütme parametreleri ve değerleri Çizelge 2'de verildi.

Çizelge 2. Veri büyütme tekniğinde kullanılan parametreler ve değerleri

\begin{tabular}{|l|c|}
\hline Parametre & Değer \\
\hline Dönüş aralığ1 & 20 \\
\hline Genişlik kaydırma aralığ1 & 0,15 \\
\hline Yükseklik kaydırma aralığı & 0,15 \\
\hline Kesme aralığ1 & 0,15 \\
\hline Yakınlaştırma aralığ1 & 0,15 \\
\hline Yatay çevirme & Doğru \\
\hline Doldurma modu & En yakın \\
\hline
\end{tabular}




\subsection{Optimizasyon Yöntemleri}

Optimizasyon yöntemlerinin temel amac1, ESA mimarisinde en iyi öğrenme gerçekleşene kadar her aşamada ağırlıkları güncellemektir [15]. Bu çalışmada, Olasılıksal Dereceli Azalma (ODA)Stochastic Gradient Descent (SGD) ve Uyarlanabilir Moment Tahmini (UMT) - Adaptive Moment Estimation (ADAM) optimizasyon yöntemleri kullanıldı. ODA yönteminde, ağırlık güncellemesi her eğitim seti için gerçekleştirildi. Bu nedenle hedefe olabildiğince erken ulaşmaya çalışıldı. ODA yönteminin formülü Eşitlik 1 'de verildi. Eşitlik 1 incelendiğinde; $\Theta$ değişseni güncellenecek ağırlık vektörünü; $\alpha$, öğrenme katsayısını ve $\nabla_{\Theta} J(\Theta)$ maliyet fonksiyonunu temsil etmektedir. Koordinat düzlemindeki özellik konumunu $x$ ve $y$ değişkenleri, temsil etmektedir [16].

$\Theta_{\mathrm{t}}=\Theta_{\mathrm{t}-1}-\alpha \nabla_{\Theta} \mathrm{J}\left(\Theta ; \mathrm{x}^{\mathrm{i}}, \mathrm{y}^{\mathrm{i}}\right)$

UMT yöntemi, her yinelemede öğrenme katsayısını güncelleyen yöntemlerden biridir. $\mathrm{Bu}$ yöntem, RMSProp yönteminin avantajları ile tasarlanmıştır. UMT yönteminin maliyetini hesaplarken Eşitlik 2 ile Eşitlik 6 arasındaki matematiksel formüller kullanılmaktadır.

$\mathrm{Bu}$ eşitliklerdeki değişkenler $m_{t}$ ve $v_{t}$ sırasıyla gradyanların tahmin edilen ilk momentini ve ikinci momentini göstermektedir. $m_{t}$ ve $v_{t}$ 'nin başlangıç değerleri genellikle sıfır olarak kabul edilmektedir. Birinci ve ikinci momentler, Eşitlik 4 ve Eşitlik 5'e göre; maliyet fonksiyonu ise Eşitlik 6'ya göre hesaplanmaktadır $[17,18]$. Bu çalışmada kullanılan diğer değerler; $\beta_{1}$ için $0,99, \beta_{2}$ için 0,99 ve $\in$ için $10^{-8}$ olarak tercih edilmiştir.

$$
\begin{aligned}
& \mathrm{m}_{\mathrm{t}}=\beta_{1} \mathrm{~m}_{\mathrm{t}-1}+\left(1-\beta_{1}\right) \mathrm{g}_{\mathrm{t}} \\
& \mathrm{v}_{\mathrm{t}}=\beta_{2} \mathrm{v}_{\mathrm{t}-1}+\left(1-\beta_{2}\right) \mathrm{g}_{\mathrm{t}}^{2} \\
& \mathrm{~m}_{\mathrm{t}}=\frac{\mathrm{m}_{\mathrm{t}}}{1-\beta_{1}^{\mathrm{t}}} \\
& v_{t}=\frac{\mathrm{v}_{\mathrm{t}}}{1-\beta_{2}^{\mathrm{t}}}
\end{aligned}
$$

$$
\theta_{\mathrm{t}+1}=\theta_{\mathrm{t}}-\frac{\eta}{\sqrt{v_{\mathrm{t}}}+\epsilon} \mathrm{m}_{\mathrm{t}}
$$

\section{3. Önerilen Yaklaşım}

Önerilen model, python yazılım dilinde tasarlandı. Mimari yapısında; evrişimsel, havuzlama, seyreltme ve yoğunluk gibi katmanları içerir [19]. Evrişimsel katman, girdi görüntüleri üzerinde filtreler $(2 \times 2,3 \times 3 \quad v b$.$) gezindirerek görüntü$ içerisinde verimli özelliklerin çıkartılmasını ve aktivasyon haritaların oluşmasını sağlamaktadır. Havuzlama katmanı, genelde evrişimsel katmanlardan sonra tercih edilmektedir ve aktivasyon girdilerinin boyutunu verimliliği etkilemeyecek şekilde düşürmektedir [20]. Seyreltme katmanı, girdi değerlerinde eş değer gördüğü değerleri yok sayarak, modelin sı ̆ bir yapıda eğitilmesini önlemektedir [21]. Yoğunluk katmanı, tam bağlantılı katman gibi modelin son katmanlarında tercih edilmektedir. Bu katman bir önceki katmandan gelen tüm çıkış değerlerini tek bir düğüm noktasında toplar ve sinıflandırma sürecinde kullanılacak fonksiyona olasılık tabanlı değerlerin hazırlanmasına yardımcı olmaktadır [22]. Önerilen modelin yapısı hakkında detaylı bilgi Çizelge 3'te verildi. Modelin girdi boyutu 224x224 olarak ayarlandı. Evrişimsel katmanların filtre boyutu $(3 \times 3,5 \times 5,8 \times 8)$ olarak seçildi. Eğitim sürecini kolaylaştırmak, zamandan kazanç sağlamak için her bir evrişimsel katman içerisinde sızdıran ReLU kullanıldı. Maksimum havuzlama katmanlarının filtre boyutu $(2 \times 2)$ seçildi ve ortalama havuzlama katmanlarının filtre boyutu (3x3) seçildi. Önerilen modelin son katmanlarına doğru seyreltme katmanı kullanıldı ve bu katman için tercih edilen oranlar 0,2 ile $0,5^{\prime}$ ti. Sınıflandırma sürecinde Softmax fonksiyonunun çıkış değeri 4 olarak ayarlandi.

Önerilen modelde kullanılan dikkat modülü girdi görüntülerinde modelin odaklanması gereken bölgeleri tespit ederek, eğitim başarımını artırmaktadır. Dikkat modülleri önerilen yaklaşımda ilgili katmandan (seyreltme katmanı) sonra blok olarak kullanıldı. Bu blok içerisinde dört adet evrişimsel katman bulunmaktadır. Girdi 
özellikleri normalizasyon işleminden geçirildikten sonra evrişimsel katmanlar tarafından (1x1) filtreler dolaştırılarak aktivasyon haritalar oluşturuldu. Aktivasyon haritalarında dikkat edilecek bölgelerin özelliklerini bulabilmek için "up_c2" fonksiyonu kullanıldı. Son aşamada ortalama havuzlama katmanı kullanılarak piksel sayısına göre yeniden ölçeklendirme yapıldı. Bu işlem "Lambda" katmanı sayesinde gerçekleşti ve dikkat bölgeleri elde edildi.

Çizelge 3. Önerilen modelin yapısı ve tercih edilmiş parametre değerleri

\begin{tabular}{|l|c|c|}
\hline Katman/Fonksiyon & Giriş kanal sayısı & Adım boyutu/Değer \\
\hline Evrişimsel & 64 & $3 \times 3$ \\
\hline Sızdıran ReLU & - & - \\
\hline Maksimum havuzlama & - & $2 \times 2$ \\
\hline Seyreltme & - & 0,5 \\
\hline Evrişimsel & 64 & $5 \times 5$ \\
\hline Sızdıran ReLU & - & - \\
\hline Maksimum havuzlama & - & $2 \times 2$ \\
\hline Seyreltme & - & 0,5 \\
\hline Evrişimsel & 16 & $8 \times 8$ \\
\hline Sızdıran ReLU & - & - \\
\hline Maksimum havuzlama & - & $2 \times 2$ \\
\hline Seyreltme & - & 0,5 \\
\hline Dikkat modül & 1 & $2 \times 2$ \\
\hline Evrişimsel & 512 & $5 \times 5$ \\
\hline Sızdıran ReLU & - & - \\
\hline Ortalama havuzlama & 512 & $3 \times 3$ \\
\hline Seyreltme & - & 0,5 \\
\hline Ortalama havuzlama & 512 & $3 \times 3$ \\
\hline Yoğunluk & 512 & - \\
\hline Sızdıran ReLU & - & - \\
\hline Yoğunluk & 512 & - \\
\hline Seyreltme & - & 0,2 \\
\hline Seyreltme & - & 0,2 \\
\hline Yoğunluk & 1024 & - \\
\hline Softmax & & Çıkıs = 4 \\
\hline
\end{tabular}

Bu çalışmada kullanılan dikkat modülünün örnek görüntü kümesi Şekil 3'te gösterildi. Sınıflandırma sürecinde önerilen modelin son katmanında Softmax fonksiyonu kullanıldı. Softmax aktivasyon fonksiyonu, genellikle ESA mimarilerinin son katmanında kullanılmaktadır. Amacı, doğrusal olmayan bir regresyon sürecinin sonunda bir önceki katmanın özelliklerinin normalize edilmesini sağlamaktır. Daha sonra normalize edilmiş değerleri olasılıklara dönüşmekte ve sinıflandırma işlemini gerçekleştirmektedir [23]. Önerilen yaklaşımın tasarımı Şekil 4'te gösterildi. Önerilen yaklaşım ile pamuk hastalığının tespitini gerçekleştirmeyi amaçlanarak tasarlandı. 


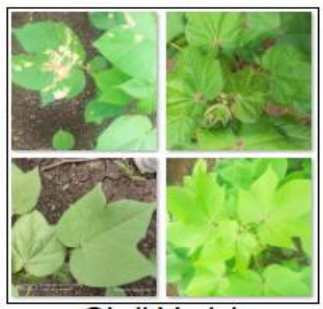

Girdi Verisi

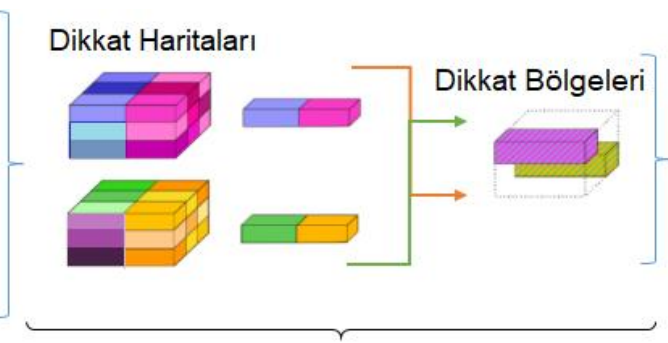

Dikkat Modülü

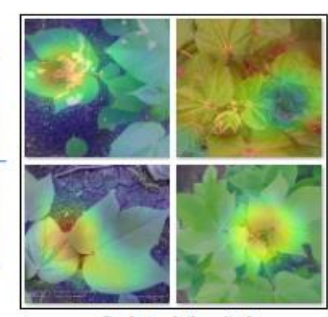

Çıktı Verisi

Şekil 3. Dikkat modülünün örnek girdi görüntüleri üzerinde uygulanması [24]

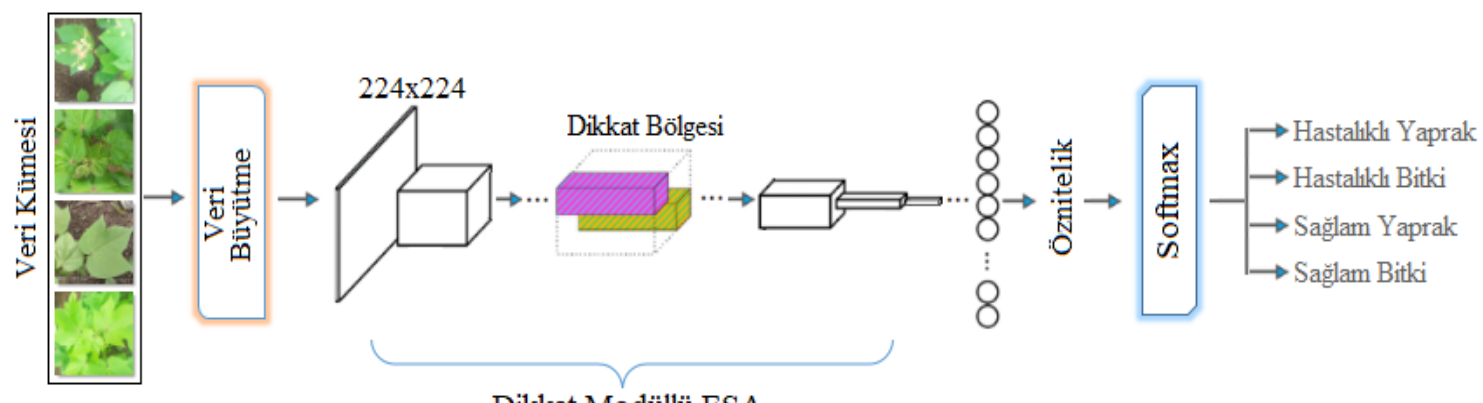

Dikkat Modüllï ESA

Şekil 4. Önerilen yaklaşımın genel tasarımı

\section{DENEYSEL SONUÇLAR}

Önerilen yaklaşım ve deneysel çalışmalar için Jupyter Notebook arayüzü kullanıldı. Yazılım kodlar1, Google Colab sunucusu kullanılarak derlendi. Donanımsal gereksinimler Google Sunucuları tarafından sağlandı. Deneysel analizler ve sonuçların değerlendirilmesi için karmaşıklık matrisi kullanıldı. Karmaşıklık matrisinin hesaplanmasında kullanılan metrikler; duyarlılık (Duy), özgüllük (Özg), hassasiyet (Has), f-skoru (F-skr) ve doğruluk (Dğr). Metrikler, Eşitlik 7 ile Eşitlik 11 arasındaki formüller ile hesaplanmaktadır. $\mathrm{Bu}$ eşitliklerde kullanılan parametreler; Doğru Pozitif (DP), Doğru Negatif (DN), Yanlış Pozitif (YP), Yanlış Negatif (YN)'dir $[25,26]$.

$$
\begin{aligned}
& \text { Duy }=\frac{D P}{D P+D N} \\
& \text { Özg }=\frac{D N}{D N+D P} \\
& \text { Has }=\frac{D P}{D P+Y P}
\end{aligned}
$$

$$
\mathrm{F}-\mathrm{skr}=\frac{2 \mathrm{xDP}}{2 \mathrm{xDP}+\mathrm{YP}+\mathrm{YN}}
$$

$\mathrm{Dg} r=\frac{\mathrm{DP}+\mathrm{DN}}{\mathrm{DP}+\mathrm{DN}+\mathrm{YP}+\mathrm{YN}}$

Çalışmanın veri seti, test ve eğitim verilerinden oluşmaktadır. Minimum seri boyutu, veri kümesinin alt görüntü kümelerine ayrılacak şekilde eş zamanlı olarak grupsal olarak seri bir şekilde model tarafından eğitilme sürecidir. Minimum seri boyutu, donanımsal gereksinimlere bağlıdır [27]. $\mathrm{Bu}$ çalışma için minimum seri boyutu 32 olarak belirlendi. Dönem sayısı, 10 tercih edildi ve kayıp fonksiyonu "kategorik çapraz entropi" seçildi. Deneysel analizler iki optimizasyon yöntemi için gerçekleştirildi. ODA optimizasyon yöntemi ile ilk deney analizi gerçekleştirildi.

ODA yöntemi ile elde edilen genel doğruluk başarısı \%95,70 olarak bulundu. Birinci analizin eğitim ve test başarı grafiği Şekil 5'te gösterildi. Hastalıklı yaprak verilerinde \%98,52; hastalıklı bitki verilerinde \%98,23; sağlam yapraklarda $\% 97,09$ ve sağlam bitkilerde \%97,37 olarak elde 
edildi. Deneyin ikinci analizinde UMT yöntemi kullanılarak sınıflandırma işlemi gerçekleştirildi. Önerilen yaklaşımın UMT yöntemi ile \%96,56 oranında genel doğruluk başarısı elde edildi. UMT yöntemi ile sınıf tabanlı doğruluk başarıları; hastalıklı yaprak verilerinde \%98,54; hastalıklı bitki verilerinde $\% 99,12$; sağlam yapraklarda $\% 97,97$ ve sağlam bitkilerde \%97,40 olarak elde edildi. Optimizasyon yöntemleri arasında UMT daha başarılı bir sonuç verdi. Ayrıca, f-skor başarısı oranında da UMT yöntemi ile gerçekleştirilen analizin diğer yöntemin analizine göre daha başarılı olduğu görüldü. İkinci analizin eğitim ve test başarı grafiği Şekil 6'da gösterildi. Deneysel analizlerden elde edilen karmaşıklık matrisleri Şekil 7'de gösterildi. Karmaşıklık matrislerinden elde edilen metrik tabanlı performans bilgileri ise Çizelge 4'te verildi. ODA yöntemi ile UMT yönteminin analiz sonuçlarının karşılaştırılması Şekil 8'de gösterildi. Tüm sınıf türlerinde UMT yöntemi ile elde edilen doğruluk oranları daha yüksekti.

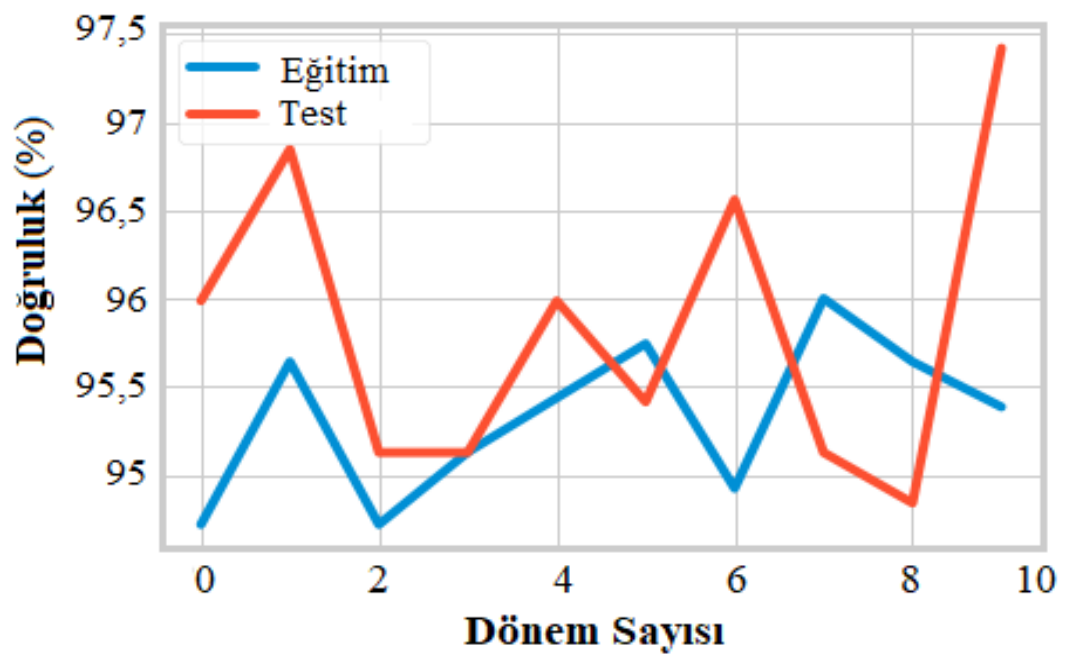

Şekil 5. Önerilen Yaklaşımın ODA optimizasyon yöntemi ile elde edilen doğruluk başarı grafiği

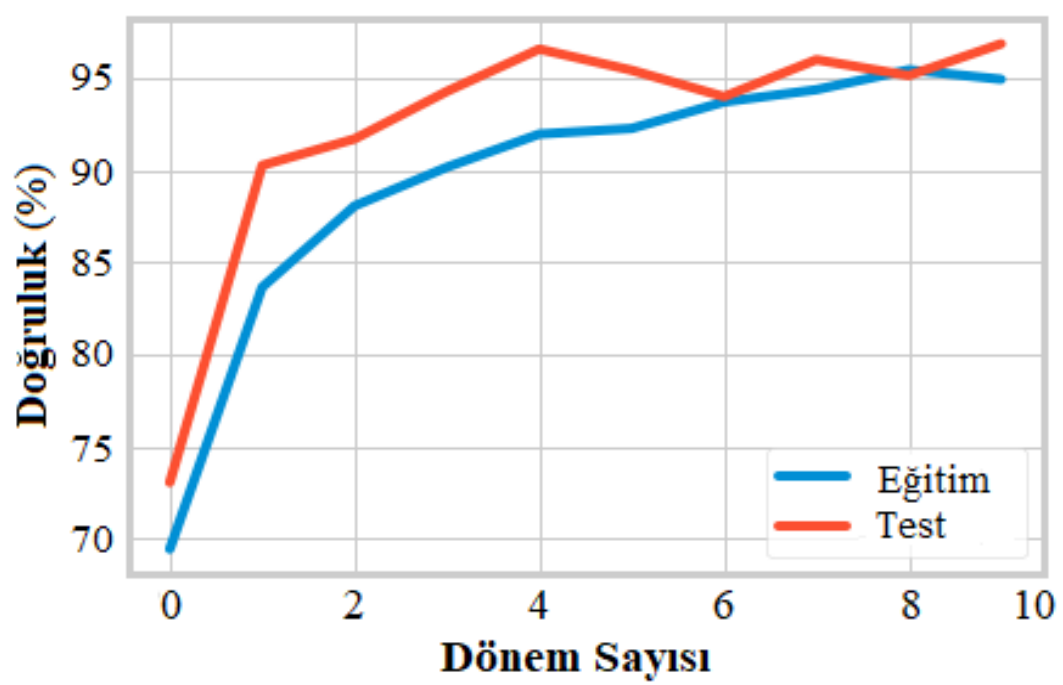

Şekil 6. Önerilen yaklaşımın UMT optimizasyon yöntemi ile elde edilen doğruluk başarı grafiği 
Tahmin Etiket

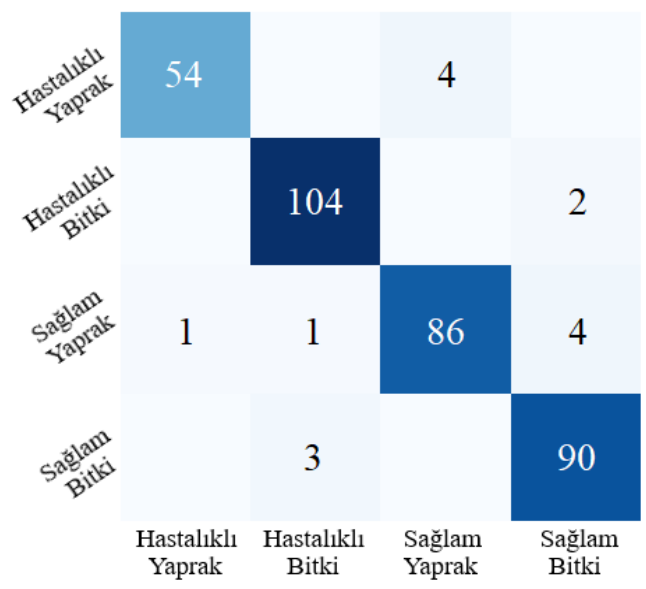

(a)

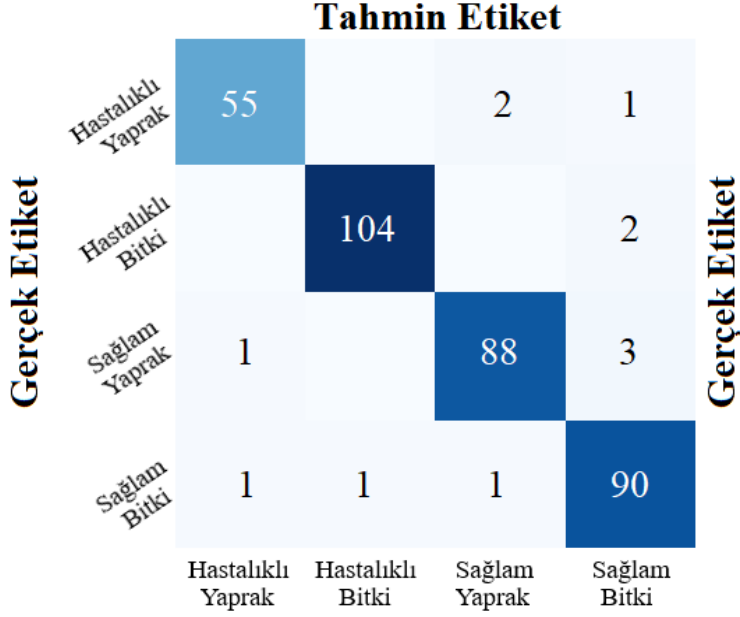

(b)

Şekil 7. Deneysel analizler sonucu tercih edilen optimizasyon yöntemine göre elde edilen karmaşıklık matrisleri; a) ODA optimizasyon yöntemi, b) UMT optimizasyon yöntemi

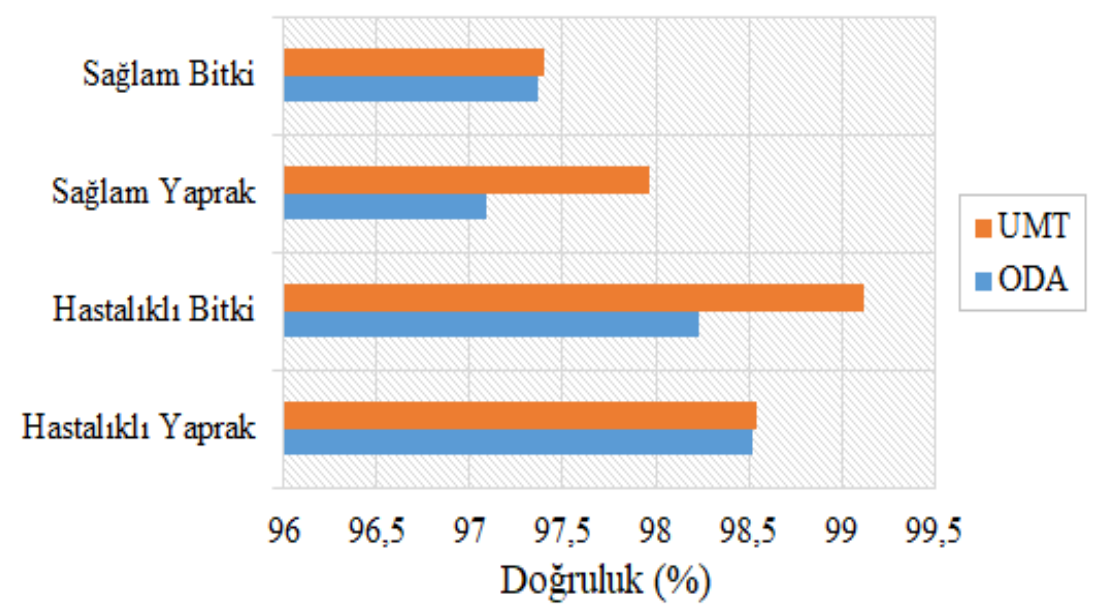

Şekil 8. Deneysel analizlerin sınıf türlerine göre karşılaştırılması

Çizelge 4. Deneysel analizlerden elde edilen karmaşıklık matrislerinin metrik sonuçları (\%)

\begin{tabular}{|c|c|c|c|c|c|c|c|}
\hline Optimizasyon & Sinıf & F-Skr. & Duy. & Özg. & Has. & Dğrr. & Genel Dğr. \\
\hline \multirow{4}{*}{ ODA } & Hastalıklı yaprak & 95,57 & 93,10 & 99,64 & 98,18 & 98,52 & \multirow{4}{*}{95,70} \\
\hline & Hastalıklı bitki & 97,19 & 98,11 & 98,29 & 96,29 & 98,23 & \\
\hline & Sağlam yaprak & 94,50 & 93,47 & 98,41 & 95,55 & 97,09 & \\
\hline & Sağlam bitki & 95,23 & 96,77 & 97,60 & 93,75 & 97,37 & \\
\hline \multirow{4}{*}{ UMT } & Hastalıklı yaprak & 95,65 & 94,83 & 99,29 & 96,49 & 98,54 & \multirow{4}{*}{96,56} \\
\hline & Hastalıklı bitki & 98,57 & 98,11 & 99,57 & 99,05 & 99,12 & \\
\hline & Sağlam yaprak & 96,17 & 95,65 & 98,81 & 96,70 & 97,97 & \\
\hline & Sağlam bitki & 95,24 & 96,77 & 97,63 & 93,75 & 97,40 & \\
\hline
\end{tabular}




\section{TARTIŞMA}

Tarımsal faaliyetlerde son zamanlarda yapay zekâ destekli birçok çalışma gerçekleşmiştir ve bu durum her geçen gün daha fazla kullanılmaktadır. $\mathrm{Bu}$ yönüyle yapay zekâ insanların ve dolayısıyla ülkelerin ekonomisini doğrudan etkileyen bir alan olarak öne çımaktadır. Ülkemizde pamuk yetiştiriciliği, ekonomik değeri olan ve birçok sanayi alanında talep gören tarımsal bir bitkidir. Dolayısıyla pamukların yetişmesini olumsuz etkileyen pamuk hastalığın erken tespiti önemlidir. Bu çalışmada, pamuk hastalığının tespiti yapılarak, bitki görüntüleri üzerinde analizler gerçekleștirildi. Önerilen yaklaşımın en önemli avantajı, dikkat modülünün görüntü verilerinde odaklanması, gereken hastalıklı bölgelerin tespit edilmesi ve modelin eğitimi için bu bölgelerin kullanması amaçlanmıştır. Böylece önerilen model eğitilirken verimli öznitelikler çıkartıldı ve modelin sinıflandırma performansına katkısı görüldü.

Önerilen yaklaşımda yöntem ve parametre tercihleri önem arz etmektedir. Nitekim, deneysel analizlerde gerçekleştirilen optimizasyon yöntemi seçiminde bile performans sonuçları arasında belirgin bir fark oluşturması, bu duruma örnektir. Önerilen yaklaşımın dezavantajlı yöntemi olarak belki de model içerisinde katmanlar ve tercih edilen parametrelerin yeniden iyileştirilmesi gerekebilir.

\section{SONUÇ}

Türkiye gibi birçok ülke tarıma dayalı bir ekonomiye sahiptir. Ülkemizde pamuk hem tarımsal faaliyetlerde hem de sanayi kollarında rağbet gören bir bitki türüdür. Güneydoğu, Akdeniz ve Ege bölgeleri pamuk yetiştiriciliğinde ön sıralarda yer almaktadır. Pamuk yetiştiriciliğinde pamuk bitkisinden elde edilen verim önemlidir. Bu verimliliği olumsuz etkileyen hastalık türlerinin erken tespiti ve gerekli müdahalelerin zamanında yapılması gerekmektedir. Bu çalışmada pamuk hastalığının tespitinde yapay zekâ destekli bir yaklaşım sunuldu. Önerilen yaklaşımın dikkat modüllerinden oluşması, derin öğrenme modelinin performansına katkı sağladı.
Ayrıca, doğru bir optimizasyon yönteminin tercihi model eğitimine katkı sunduğu bu çalışmada görüldü. UBT optimizasyon yöntemi ile hastalıklı yaprak verilerinde \%98,54; hastalıklı bitki verilerinde $\% 99,12$; sağlam yapraklarda $\% 97,97$ ve sağlam bitkilerde \%97,40 doğruluk oranları elde edildi.

Gelecek çalışmada, dikkat modüllerini farklı yöntem ve yaklaşım içeren yapay zekâ destekli modeller üzerinde eğitimi gerçekleştirilecektir ve çeşitli makine öğrenme yöntemleri ile başarıları kıyaslanacaktır.

\section{KAYNAKLAR}

1. Chohan, S., Perveen, R., Abid, M., Tahir, M.N., Sajid, M., 2020. Cotton Diseases and Their Management BT-Cotton Production and Uses: Agronomy. Crop Protection, and Postharvest Technologies. In: Ahmad S, Hasanuzzaman M (eds). Springer Singapore, Singapore, 239-270.

2. Eski, Ö., Kayalak, S., 2018. Türkiye'de Pamuk Üretimi için Bir Öngörü Modeli: Var Yaklaşımı. ÇOMÜ Ziraat Fakültesi Dergisi, 6, 131-137. https://doi.org/10.33202/comuagri.503960.

3. 2019 Pamuk Bülteni, https://www.tarimorman.gov.tr, Erișim Tarihi: 09.08.2020.

4. Çoban, M., Çiçek, S., Küçüktaban, F., Yazıcı, L., Çiftçi, H., 2016. Bazı Pamuk Melezlerinin Verim ve Lif Kalite Özelliklerinin İncelenmesi. Tarla Bitkileri Merkezi Araştırma Enstitüsü Dergisi, 25(2), 112-112. https://doi.org/ 10.21566/tarbitderg.281873.

5. Copur, O., 2018. GAP Projesinin Türkiye Pamuk Üretimine Etkisi: Son On Ylldaki Değişimler. Adyütayam, 6(1), 11-18.

6. Çelik, İ., Soysal, M., İnan, Ö., Çetinkaya, M., 2010. Antalya Bölgesinde Pamuk Solgunluk Hastalı̆̆ 1 (Verticillium dahliae) Surveyi. Batı Akdeniz Tarımsal Araştırma Enstitüsü Derim Dergisi, 27(1), 18-32.

7. Sakçı, N., Sağır, A., Temiz, M.G., 2017. Pamukta Solgunluk Hastalığı (Verticillium Dahliae Kleb.)'nın Tohumun İçeriğine Etkisinin Belirlenmesi. Bitki Koruma Bülteni, 57(1),1-11. https://doi.org/10.16955/bitkorb.299002. 
8. Ferro, H.M., Souza, R.M., Lelis, F.M.V., Silva, J.C.P., Medeiros, F.H.V.D., 2020. Bacteria for Cotton Plant Protection: Disease Control Crop Yield and Fiber Quality. Rev Caatinga 33(1), 43-53.

9. Shah, N., Jain, S., 2019. Detection of Disease in Cotton Leaf using Artificial Neural Network. In: 2019 Amity International Conference on Artificial Intelligence, 473-476.

10. Chowdhary, K.N., Nithin, Y.M., Srikanta, P., Rekha, B.S., 2018. A Machine Learning Approach for Detection of Cotton Leaf Disease. Int. J. Sci. Res. Dev., 6(3), 1902-1905.

11.Pechuho, N., Khan, Q., Kalwar, S., 2020. Cotton Crop Disease Detection using Machine Learning via Tensorflow. Pakistan J. Eng. Technol., SI(1), 126-130.

12. Gulhane, V.A., Gurjar, A.A., 2011. Detection of Diseases on Cotton Leaves and its Possible Diagnosis. Int J Image, 5(5), 590-598.

13. Bhoi, J., 2020. Cotton Disease Dataset. In: Kaggle.https://www.kaggle.com/janmejaybhoi/ cotton-disease-dataset. Accessed 29 Oct 2020.

14. Shorten, C., Khoshgoftaar, T.M., 2019. A Survey on Image Data Augmentation for Deep Learning. J. Big Data, 6(60), 1-48. https://doi.org/10.1186/s40537-019-0197-0

15.Sun, S., Cao, Z., Zhu, H., Zhao, J., 2020. A Survey of Optimization Methods from a Machine Learning Perspective. IEEE Trans Cybern, 50, 3668-3681. https://doi.org/ 10.1109/tcyb.2019.2950779

16. Kennedy, R.K.L., Khoshgoftaar, T.M., Villanustre, F., Humphrey, T., 2019. A Parallel and Distributed Stochastic Gradient Descent Implementation Using Commodity Clusters. J. Big Data, 6(16) 1-23. https://doi.org/10.1186/s40537-019-0179-2.

17. Kumar, A., Sarkar, S., Pradhan, C., 2020. Malaria Disease Detection Using CNN Technique with SGD, RMSprop and ADAM Optimizers. In: Journal of Ambient Intelligence and Humanized Computing, 211-230.

18.Zhong, H., Chen, Z., Qin, C., Huang, Z., Zheng, V.W., Xu, T., Chen, E., 2020. Adam Revisited: A Weighted Past Gradients Perspective. Front Comput Sci, 14(5), 145309. https://doi.org/10.1007/s11704-019-8457-x.

19. Chauhan, K., 2020. CNN-Attention: An Image
Classifier with Attention Layers Visualized. In: GitHub.https://github.com/kapilnchauhan77/C NN-Attention. Accessed 31 Oct 2020.

20. Suárez-Paniagua, V., Segura-Bedmar, I., 2018. Evaluation of Pooling Operations in Convolutional Architectures for Drug-drug Interaction Extraction. BMC Bioinformatics 19, 209. https://doi.org/10.1186/s12859-018-2195-1.

21. Jiang, X., Lu, M., Wang, S.H., 2020. An Eightlayer Convolutional Neural Network with Stochastic Pooling, Batch Normalization and Dropout for Fingerspelling Recognition of Chinese Sign Language. Multimed Tools Appl 79, 15697-15715. https://doi.org/10.1007/s11042-019-08345-y.

22. Yang, Y., Wu, Q.M.J., Feng, X., Akilan, T., 2020. Recomputation of the Dense Layers for Performance Improvement of DCNN. IEEE Trans Pattern Anal Mach Intell, 42, 2912-2925. https://doi.org/10.1109/tpami.2019.2917685

23. Luo, Y., Wong, Y., Kankanhalli, M., Zhao, Q., 2020. Softmax: Improving Intraclass Compactness and Interclass Separability of Features. IEEE Trans Neural Networks Learn Syst, 31, 685-699. https://doi.org/10.1109/tnnls.2019.2909737

24. Bello, I., Zoph, B., Le, Q.V., Vaswani, A., Shlens, J., 2019. Attention Augmented Convolutional Networks. Proc IEEE Int Conf Comput Vis 2019-Octob: 3286-3295. https://doi.org/10.1109/ICCV.2019.00338.

25. Gadekallu, T.R., Khare, N., Bhattacharya, S., Singh, S., Maddikunta, P.K.R., Srivastava, G., 2020. Deep Neural Networks to Predict Diabetic Retinopathy. J Ambient Intell Humaniz Comput. https://doi.org/10.1007/s12652-020-01963-7.

26. Chicco, D., Jurman, G., 2020. The Advantages of the Matthews Correlation Coefficient (MCC) Over F1 Score and Accuracy in Binary Classification Evaluation. BMC Genomics, 21, 6. https://doi.org/10.1186/s12864-019-6413-7.

27. Kandel, I., Castelli, M., 2020. The Effect of Batch Size on the Generalizability of the Convolutional Neural Networks on a Histopathology Dataset, ICT Express. https://doi.org/https://doi.org/10.1016/j.i cte.2020.04.010. 